\title{
Development and evaluation of a method for calculating the Healthy Eating Index-2005 using the Nutrition Data System for Research
}

\author{
Paige E Miller ${ }^{1}{ }^{*}$, Diane C Mitchell ${ }^{1}$, Priscilla L Harala ${ }^{2}$, Janet M Pettit ${ }^{2}$, Helen \\ Smiciklas-Wright ${ }^{1}$ and Terryl J Hartman ${ }^{1}$ \\ 'Department of Nutritional Sciences, The Pennsylvania State University, 110 Chandlee Laboratory, \\ University Park, PA 16802, USA: ${ }^{2}$ Division of Epidemiology and Community Health, \\ Nutrition Coordinating Center, University of Minnesota, Minneapolis, MN, USA
}

Submitted 19 May 2009: Accepted 27 April 2010: First published online 25 June 2010

\begin{abstract}
Objective: To develop and evaluate a method for calculating the Healthy Eating Index-2005 (HEI-2005) with the widely used Nutrition Data System for Research (NDSR) based on the method developed for use with the US Department of Agriculture's (USDA) Food and Nutrient Dietary Data System (FNDDS) and MyPyramid Equivalents Database (MPED).

Design: Cross-sectional.

Setting: Non-institutionalized, community-dwelling adults aged 70 years and above. Subjects: Two hundred and seventy-one adults participating in the Geisinger Rural Aging Study (GRAS) and 620 age- and race-matched adults from the National Health and Nutrition Examination Survey 2001-2002 (NHANES) were included in the analysis. The HEI-2005 scores were generated using NDSR in GRAS and compared to scores generated using FNDDS and MPED in NHANES.

Results: Similar total HEI-2005 scores (mean 62.0 (SE 0.75) in GRAS $v .57 \cdot 4$ (sE 0.55) in NHANES) were estimated, and the individual components most strongly correlated with total score in both samples were compared. Cronbach's coefficient $\alpha$ values of HEI-2005 were 0.52 in GRAS and 0.43 in NHANES.

Conclusions: Since NDSR is commonly used for educational purposes, in clinical settings and in nutrition research, it is important to develop methodology for assessing diet quality through the use of HEI-2005 with this dietary analysis software application and its accompanying food and nutrient database. Results from the present study show that HEI-2005 scores can be generated with NDSR using the method described in the present study and the detailed USDA Center for Nutrition Policy and Promotion technical report as guidance.
\end{abstract}

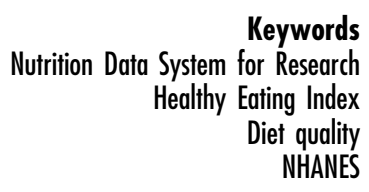

A number of studies have assessed the diet of individuals and populations in terms of single foods, food groups, nutrients or other individual dietary components. An alternative approach is to examine the overall diet quality to reflect the complexity of food intake patterns and dietary exposure. By examining the totality of the diet through diet indices or scores, insight may be gained into the combined effects of foods, nutrients and other dietary components on various health outcomes ${ }^{(1)}$. The use of diet indices or scores designed to measure adherence to pre-established criteria may be an effective approach in the study of diet as a multi-dimensional exposure in relation to health outcomes ${ }^{(2-8)}$.

The Healthy Eating Index (HEI) is one such tool originally developed in 1995 by the United States Department of Agriculture's (USDA) Center for Nutrition Policy and
Promotion (CNPP) to monitor and evaluate change in diet quality among the US population ${ }^{(9)}$. The HEI and similarly structured tools are designed to measure compliance with established dietary guidance ${ }^{(3,7,10)}$. They have been used for a variety of purposes, including evaluations of lifestyle interventions based in the community, school, home and clinical settings ${ }^{(11-15)}$, comparisons of popular $\operatorname{diets}^{(16)}$, population-level surveillance of diet quality and dietary patterns ${ }^{(9,10,17-19)}$ and epidemiological investigations of diet-disease associations ${ }^{(5,12,16,20-25)}$. The CNPP recently revised the HEI to measure compliance with the key recommendations found in the 2005 'Dietary Guidelines for Americans, ${ }^{(6,26)}$. Twelve individual components that correspond to these recommendations ${ }^{(27)}$ are included in the revised HEI (HEI-2005): total fruit, whole fruit, total vegetables, dark green and orange vegetables and 
legumes, total grains, whole grains, milk, meat and beans, oils, saturated fat, sodium and energy from solid fat, alcoholic beverages and added sugars (SoFAAS). Solid fats are sources of both saturated and trans fat; alcoholic beverages refer to the ethanol in alcoholic beverages and the carbohydrates in beer and wine. A recent evaluation of the HEI-2005 with dietary data collected as a part of the National Health and Nutrition Examination Survey 2001-2002 (NHANES) with the USDA's automated multiple-pass method (AMPM) and its accompanying databases (Food and Nutrient Dietary Data System (FNDDS) and MyPyramid Equivalents Database (MPED) version $1 \cdot 0$ (USDA, Agricultural Research Services, Nutrition Research Group, Beltsville, MD, USA) $)^{(28)}$ found the index to be a reliable and valid measure of diet quality ${ }^{(29)}$.

A method to calculate HEI-2005 scores using the USDA MPED and NHANES dietary data collected with AMPM is described in a recent publication ${ }^{(6)}$, and the corresponding SAS code (SAS statistical software package version 9•1; SAS Institute Inc., Cary, NC, USA) is publicly available (http:// www.cnpp.usda.gov/). Since a variety of data analysis software applications and food composition databases other than FNDDS and MPED are commonly used in nutrition research ${ }^{(30,31)}$, it is important to develop methodology for assessing diet quality through the use of HEI-2005 with different applications and their accompanying databases. The Nutrition Data System for Research (NDSR) and its associated food composition database (Nutrition Coordinating Center (NCC) Food and Nutrient Database) are widely used to collect $24 \mathrm{~h}$ dietary recalls and to analyse data from dietary recalls and food records ${ }^{(31-35)}$. Therefore, the primary aim of the present study was to develop a method for calculating HEI-2005 using NDSR. The secondary aim was to evaluate the method by calculating HEI-2005 scores with NDSR in a subset of older adults who completed $24 \mathrm{~h}$ dietary recalls as a part of the Geisinger Rural Aging Study (GRAS). These scores were compared to those calculated with the USDA's FNDDS and MPED in an ageand race-matched sample from NHANES.

\section{Methods}

\section{GRAS and NHANES samples}

Two independent samples were used in the present study. One sample included a subset ( $n$ 271) of communitydwelling older adults aged 70 years and above who were enrolled in GRAS, a longitudinal, nutritional-risk screening cohort study (20000 Pennsylvanians). This subset of older adults had agreed to participate in a separate FFQ validation study in 2004-2005. Letters describing the validation study were originally mailed to 1930 individuals who were selected using a computer-generated random scheme. There were $74 \%$ ( $n$ 1432) who met the initial eligibility criteria: free-living and residing within $120 \mathrm{~km}$ of a Geisinger medical clinic participating in the study. Of these older adults, $19 \%$ ( $n$ 271) agreed to participate, attended a clinic visit, were free from major depressive disorders (Geriatric Depression Scale with a score of $\leq 6^{(36)}$ ) and cognitive impairment (Mini-Mental State Examination score $\geq 23^{(37)}$, and completed four $24 \mathrm{~h}$ dietary recalls. A sample size of at least 200 individuals was determined to be sufficient for the FFQ validation study according to power and sample size calculations. A detailed description of the GRAS cohort has been published previously ${ }^{(38)}$.

Comparative analysis was performed with an age- and race-matched subset ( $n$ 620) of the participants in NHANES 2001-2002, a cross-sectional, nationally representative survey of the US non-institutionalized civilian population conducted by the National Center for Health Statistics (NCHS), Centers for Disease Control and Prevention (CDC). Since all GRAS participants were over the age of 70 years and $99 \%$ of the GRAS sample were nonHispanic whites, only non-Hispanic whites aged 70 years and above who completed the $24 \mathrm{~h}$ dietary recall in NHANES were included in the present study. Individuals with unreliable dietary data who did not meet the minimum criteria for completeness were excluded ${ }^{(39)}$. Details pertaining to the sampling procedures, study design and survey content in NHANES are documented in a previous publication $^{(39)}$ and are available on the NCHS/CDC website (http://www.cdc.gov/nchs/nhanes.htm).

\section{Data collection in GRAS}

All GRAS participants attended a clinic within the Geisinger Health Care System between 2004 and 2005, where demographic, anthropometric and other health-related data were collected. Height and weight were measured with a stadiometer (Infant/Child/Adult Height Measuring Board; Shorr Productions, LLC, Olney, MD, USA) and a portable digital scale (Tanita Corporation of America, Inc., Arlington Heights, IL, USA), respectively; BMI $\left(\mathrm{kg} / \mathrm{m}^{2}\right)$ was calculated from these values. Waist circumference was measured with a flexible, non-elastic measuring tape according to standardized procedures established for use in NHANES ${ }^{(40)}$. All study procedures were approved by the Geisinger Health Care System and The Pennsylvania State University human investigation review boards.

\section{GRAS dietary data collection and calculation of HEI-2005 with NDSR}

Trained interviewers at The Pennsylvania State University Diet Assessment Center collected four $24 \mathrm{~h}$ dietary recalls by telephone from each participant on unannounced, random, non-consecutive days over a 10-month time period. Participants completed recalls on three weekdays and one weekend day. All dietary data were collected and analysed using NDSR software version 2005 developed by the NCC, University of Minnesota, Minneapolis, MN, USA. The computer-assisted, interviewer-administered dietary recalls were facilitated by an automated four-stage multiplepass technique ${ }^{(41,42)}$. Both interviewers and participants 
Table 1 Method to calculate the HEl-2005 with NDSR

\begin{tabular}{|c|c|c|c|}
\hline HEI-2005 component & NDSR output file & Units for calculation & Calculations required \\
\hline Total fruit (includes $100 \%$ juice) & Servings* & Cup $/ 4 \cdot 2 \mathrm{~kJ}(1 \mathrm{kcal}) \S$ & Convert servings to cups ( 1 serving $=0.5$ cup equivalent) \\
\hline Whole fruit (not juice) & Servings & Cup/4.2 kJ & Convert servings to cups ( 1 serving $=0.5$ cup equivalent) \\
\hline Total vegetables & Servings & Cup/4.2 kJ & $\begin{array}{l}\text { Convert servings to cups ( } 1 \text { serving }=0.5 \text { cup } \\
\text { equivalent })\end{array}$ \\
\hline $\begin{array}{l}\text { Dark green and orange } \\
\text { vegetables and legumes }\end{array}$ & Servings & Cup $/ 4 \cdot 2 \mathrm{~kJ}$ & $\begin{array}{l}\text { Convert servings without legumes to cups } \\
\text { ( } 1 \text { serving }=0.5 \text { cup equivalent); include legumes } \\
\text { not counted to meet the meat and beans standard }\end{array}$ \\
\hline Total grains & Servings & Ounce $/ 4 \cdot 2 \mathrm{~kJ} \|$ & 1 serving $=1$ ounce equivalent \\
\hline Whole grains & Servings & Ounce $/ 4 \cdot 2 \mathrm{~kJ}$ & $\begin{array}{l}1 \text { serving 'some whole grain' }=0.5 \text { ounce equivalent } \\
\text { refined grain }+0.5 \text { ounce equivalent whole grain; } 1 \\
\text { serving 'whole grain' }=1 \text { ounce equivalent whole grain }\end{array}$ \\
\hline Milk & Servings & Cup/4.2 kJ & 1 serving $=1$ cup equivalent ${ }^{\star \star}$ \\
\hline Meat and beans & Servings & Ounce $/ 4 \cdot 2 \mathrm{~kJ}$ & $\begin{array}{l}1 \text { serving }=1 \text { lean meat ounce equivalent; if the meat and } \\
\text { beans standard is not met, } 1 \text { serving legumes = } 2 \text { lean } \\
\text { meat ounce equivalents }\end{array}$ \\
\hline Oils & $\begin{array}{l}\text { Components/ } \\
\text { ingredientst }\end{array}$ & $\mathrm{g} / 4 \cdot 2 \mathrm{~kJ}$ & $\begin{array}{l}\text { Total fat }(\mathrm{g}) \text { from fish, nuts, seeds and other food items } \\
\text { with non-hydrogenated vegetable oilstt }\end{array}$ \\
\hline Saturated fat & Nutrientsł & Percentage of total $\mathrm{kJ}$ & - \\
\hline Sodium & Nutrients & $\mathrm{g} / 4 \cdot 2 \mathrm{~kJ}$ & - \\
\hline $\begin{array}{l}\text { Energy from solid fat, alcoholic } \\
\text { beverages and added sugar }\end{array}$ & $\begin{array}{l}\text { Nutrients and } \\
\text { Components/ } \\
\text { ingredients }\end{array}$ & Percentage of total $\mathrm{kJ}$ & $\begin{array}{l}\text { Added sugar }(\mathrm{g}) \text { and ethanol }(\mathrm{g}) \text { obtained from the } \\
\text { nutrients file; carbohydrates from beer and wine }(\mathrm{g}) \text { and } \\
\text { solid fat }(\mathrm{g}) \text { obtained from the Ingredients file } \neq \ddagger\end{array}$ \\
\hline
\end{tabular}

HEl-2005, Healthy Eating Index-2005; NDSR, Nutrition Data System for Research.

*Serving count food file.

tComponent/ingredient file.

tNutrient intake properties file.

§Cup equivalent.

\|Ounce equivalent.

-One cup raw leafy green vegetables = one serving = one cup equivalent.

${ }^{* *}$ One cup milk or yoghurt, 1.5 ounce natural cheese, 2 ounces processed cheese, 2 cups cottage cheese and 0.5 cup evaporated milk $=1$ cup equivalent. t+Includes total fat from mayonnaise, oil-based salad dressings, margarine (tub, liquid, spread, squeeze or unspecified type if fat content is $<80 \%$ ), oil-based condiments and oil-based snack items (e.g. potato chips, popcorn and corn tortilla chips).

$\ddagger \ddagger$ Solid fat includes the excess fat $(\mathrm{g})$ from animal meats and dairy; hydrogenated oils $(\mathrm{g})$ used in frying foods such as French fries; and the total fat ( $\mathrm{g}$ ) from food items in which the predominant fat(s) were saturated and/or trans fat (e.g. gravy, prepackaged cakes, chocolate candy and cream-based sauces).

had access to posters that displayed two-dimensional illustrations of cups, spoons, bowls and other common food shapes to assist with portion size estimation (2-D Food Portion Visual; Nutrition Consulting Enterprises, Framingham, MA, USA).

Three separate NDSR output files were used to calculate the HEI-2005 individual component scores (Table 1). The Serving Count Food File was used to create scores for eight of the components: total fruit, whole fruit, total vegetables, dark green and orange vegetables and legumes, total grains, whole grains, milk and meat and beans. The sodium and saturated fat components, as well as the added sugar and a portion of the alcoholic beverages (grams of ethanol) subcomponent of SoFAAS, were calculated from the Intake Properties File. The Component/Ingredient File was used to create scores for the oil component, the solid fat subcomponent and the remaining part of the alcoholic beverages subcomponent (grams of carbohydrate from beer and wine).

The $4 \mathrm{~d}$ average energy $(\mathrm{kJ})$ intake was used for all component calculations. When generating component scores from the Serving Count Food File, daily servings of the respective food or beverage items were averaged across the four recalls, and cup or ounce equivalents per $4 \cdot 2 \mathrm{~kJ}$ ( $1 \mathrm{kcal}$ ) consumed consistent with MPED were determined. Since NDSR separates grains into 'refined grain', 'some grain' and 'whole grain', food items that were labelled 'some grain' were considered to be one-half whole grain and one-half refined grain, and the servings were appropriated accordingly. Daily grams of sodium, added sugar, saturated fat, and ethanol from beer, wine and liquor consumed as beverages were retrieved from the Intake Properties File and averaged across $4 \mathrm{~d}$ for each individual. Daily grams of sodium were determined per $4 \cdot 2 \mathrm{~kJ}$ consumed. Grams of saturated fat, ethanol and added sugar were multiplied by $37 \cdot 8,29 \cdot 4$ and $16 \cdot 8 \mathrm{~kJ} / \mathrm{g}$ ( 9,7 and $4 \mathrm{kcal} / \mathrm{g}$ ), respectively. The percentage of total energy from saturated fat was determined, and the energy from added sugar and ethanol were combined with the energy from solid fat and carbohydrates from beer and wine (described below) to calculate the percentage of total energy from SoFAAS.

The third file used to calculate HEI-2005 scores was the Component/Ingredient File. This file provided the dietary information required to determine scores for the oil component, the solid fat subcomponent and the remaining portion of the alcoholic beverages subcomponent (i.e. carbohydrates from beer and wine consumed as beverages). Carbohydrates from wine and beer used as ingredients in cooking were not included. Several assumptions were necessary for the oil and solid fat calculations since NDSR does not separate all food items, 
such as store-bought baked goods and prepackaged snack items, into their constituent parts. Grams of total fat from non-hydrogenated vegetable oils and oils in fish, nuts and seeds were included in the oil component score. Total fat from the following food items was included in the oil component calculation: mayonnaise, oil-based salad dressings, margarine (tub, liquid, spread, squeeze or unspecified type if fat content is $<80 \%$ ), oil-based condiments (e.g. tartar sauce) and oil-based snack items such as potato chips, popcorn and corn tortilla chips. These food items were not separated into individual ingredients by NDSR, but contained mainly oil as the type of fat. The grams of fat from oil were summed by day and averaged across $4 \mathrm{~d}$ for each individual. Scores were determined per $4 \cdot 2 \mathrm{~kJ}$ consumed.

Scores for solid fat were generated by summing the (i) excess fat (g) from animal meats and dairy products; (ii) total fat (g) from lard and meat drippings as well as dairy products that are primarily fat (e.g. butter, cream and cream cheese); (iii) total fat (g) from stick margarine (or unspecified type of margarine if fat content is $>80 \%$ ); (iv) hydrogenated oils (g) used in frying foods such as French fries; and (v) total fat (g) from food items where the predominant fat(s) were saturated and/or trans fat (e.g. gravy, prepackaged cakes and chocolate). The excess fat in meat and poultry is considered the total fat less the allowable fat $(9 \cdot 28 \mathrm{~g} / 100 \mathrm{~g}$ of food), whereas the excess fat in dairy products is considered the fat beyond the amount that would be consumed if the lowest fat variety (e.g. skimmed milk or non-fat yoghurt) had been selected. The total fat from certain food items, such as prepackaged cakes, candy, cookies and other storebought desserts, was used in the solid fat component calculation because these items are not separated into individual ingredients by NDSR but are considered to contain mainly saturated or trans fat as the type of fat. The total grams of solid fat were summed by day, averaged across the $4 \mathrm{~d}$, and multiplied by $37 \cdot 8 \mathrm{~kJ} / \mathrm{g}$. The energy from solid fat was combined with energy from added sugar, ethanol and carbohydrates from beer and wine, and the percentage of total energy from these subcomponents was generated. The final assignment of scores for each component followed the guidelines established by the CNPP, which are detailed in a technical report ${ }^{(43)}$.

\section{NHANES dietary data collection and calculation of HEI-2005 with MPED}

One-day dietary intake data in NHANES were collected via in-person $24 \mathrm{~h}$ dietary recalls by trained interviewers using AMPM, which includes an automated, five-stage multiplepass system ${ }^{(39)}$. HEI-2005 total and component scores were calculated from the NHANES dietary data using a documented SAS code (Statistical Analysis Software Package version 9·1; SAS Institute Inc., Cary, NC, USA) available on the USDA CNPP website (http://www.cnpp.usda.gov/). The SAS code was created by Guenther et al. ${ }^{(29)}$ to calculate
HEI-2005 scores using MPED, along with an additional database (i.e. CNPP's MPED for Whole Fruit and Fruit Juice) and NHANES data. The publicly available code was used previously by Guenther et al. ${ }^{(29)}$ to evaluate the validity and reliability of the diet quality measure. The development and evaluation of the HEI-2005 are described in two recent publications $^{(6,29)}$.

\section{Statistical analysis}

The sample weights provided for analysis with the NHANES's 1-day $24 \mathrm{~h}$ dietary recall data were used to account for the differential probabilities of selection into the sample, non-response and non-coverage ${ }^{(39)}$. Since dietary intake differs between weekdays and weekends, the sample weights also adjust for day of the week. Demographic and health-related variables were summarized with means and standard errors for continuous variables and percentages for categorical variables. In analyses comparing nutrient intakes between GRAS and NHANES, the nutrient density approach was used to account for total energy intake - total fat and protein were expressed as percentages of total energy while dietary fibre and micronutrients were expressed as intakes per $4.2 \mathrm{~kJ}^{(44)}$. The percentage difference in the summary score and each component score between GRAS and NHANES was calculated by the following equation: ([GRAS mean score - NHANES mean score)/GRAS mean score] $X$ 100. The GRAS and NHANES participants were compared with Student's $t$ tests for continuous data and $\chi^{2}$ tests for categorical data. Cronbach's coefficient $\alpha$ was used to measure the internal consistency of the HEI-2005 individual components in both samples. Pearson's correlation coefficients between each individual component and the total score - less the individual component in the correlation test - were examined to determine which components had the greatest influence on the HEI-2005 summary scores in GRAS and NHANES. A $P$ value of $<0.05$ was considered statistically significant for all statistical tests. The publicly available method for generating HEI-2005 scores is an SAS code ${ }^{(6)}$; therefore, SAS statistical software package version $9 \cdot 1$ was used for the generation of HEI-2005 scores with NHANES data. To account for the complex survey design of NHANES data, STATA statistical software package version $10 \cdot 1$ (StataCorp., College Station, TX, USA) survey commands were used for statistical analyses.

\section{Results}

Table 2 provides summary statistics for NHANES and GRAS. There were $82 \%$ of GRAS participants compared to $72 \%$ of NHANES participants who had at least a high school education $(P<0 \cdot 001)$. Mean BMI values were comparable between GRAS and NHANES $\left(28.0 \mathrm{~kg} / \mathrm{m}^{2} v .27 \cdot 5 \mathrm{~kg} / \mathrm{m}^{2}\right.$, respectively), whereas mean waist circumference was modestly lower in GRAS compared with NHANES $(95.7 \mathrm{~cm} v .99 \cdot 4 \mathrm{~cm}$, respectively). Total energy intake and 
Table 2 Comparison of demographic and health-related characteristics and nutrient intakes between participants in the GRAS and the NHANES 2001-2002

\begin{tabular}{|c|c|c|c|c|c|}
\hline \multirow[b]{2}{*}{ Characteristic } & \multicolumn{2}{|c|}{$\begin{array}{l}\text { GRAS } \\
(n 271)\end{array}$} & \multicolumn{2}{|c|}{$\begin{array}{l}\text { NHANES 2001-2002 } \\
(n \text { 620) }\end{array}$} & \multirow[b]{2}{*}{$P$ value $^{*}$} \\
\hline & Mean & SE & Mean & SE & \\
\hline Age (years) & $78 \cdot 6$ & $0 \cdot 24$ & $77 \cdot 3$ & $0 \cdot 20$ & $<0.01$ \\
\hline Race (\% non-Hispanic white) & $98 \cdot 9$ & - & $100 \cdot 0$ & - & - \\
\hline Gender (\% male) & $41 \cdot 7$ & - & $43 \cdot 2$ & - & 0.45 \\
\hline High school education or higher (\%) & $81 \cdot 9$ & - & $72 \cdot 3$ & - & $<0.01$ \\
\hline Current tobacco use (\%) & $5 \cdot 2$ & - & $6 \cdot 8$ & - & 0.09 \\
\hline BMI $\left(\mathrm{kg} / \mathrm{m}^{2}\right)$ & $28 \cdot 0$ & $0 \cdot 32$ & $27 \cdot 5$ & $0 \cdot 19$ & $0 \cdot 15$ \\
\hline Waist circumference $(\mathrm{cm})$ & $95 \cdot 7$ & 0.93 & $99 \cdot 4$ & 0.53 & $<0.01$ \\
\hline \multicolumn{6}{|l|}{ Nutrient variables } \\
\hline Energy intake (kJ) & $6 \cdot 3$ & $0 \cdot 11$ & $7 \cdot 1$ & $0 \cdot 10$ & $<0.01$ \\
\hline Fat $(\%$ of $\mathrm{kJ})$ & $32 \cdot 3$ & $0 \cdot 39$ & $34 \cdot 0$ & 0.35 & $<0.01$ \\
\hline Protein (\% of kJ) & $16 \cdot 6$ & $0 \cdot 21$ & $15 \cdot 5$ & $0 \cdot 18$ & $<0.01$ \\
\hline Dietary fibre per $4 \cdot 2 \mathrm{~kJ}(\mathrm{~g})$ & $10 \cdot 5$ & $0 \cdot 20$ & $9 \cdot 4$ & $0 \cdot 18$ & 0.88 \\
\hline Vitamin C per $4.2 \mathrm{~kJ}(\mathrm{mg})$ & $57 \cdot 3$ & $1 \cdot 88$ & $54 \cdot 6$ & 1.98 & $0 \cdot 32$ \\
\hline Folate per $4 \cdot 2 \mathrm{~kJ}$ (DFE) & $328 \cdot 6$ & $8 \cdot 77$ & $309 \cdot 8$ & $7 \cdot 67$ & 0.08 \\
\hline Calcium per $4.2 \mathrm{~kJ}(\mathrm{mg})$ & 479.5 & $10 \cdot 99$ & 453.9 & $10 \cdot 38$ & 0.03 \\
\hline
\end{tabular}

GRAS, Geisinger Rural Aging Study; NHANES, National Health and Nutrition Examination Study; DFE, dietary folate equivalents.

${ }^{\star} P$ values obtained from Student's $t$ tests for continuous variables and $\chi^{2}$ tests for categorical variables.

Table 3 Total HEI-2005 and component scores in GRAS and NHANES 2001-2002 samples

\begin{tabular}{|c|c|c|c|c|c|c|c|}
\hline \multirow[b]{2}{*}{ Component } & \multirow{2}{*}{$\begin{array}{l}\text { Range of } \\
\text { score }\end{array}$} & \multicolumn{2}{|c|}{$\begin{array}{l}\text { GRAS } \\
(n 271)\end{array}$} & \multicolumn{2}{|c|}{$\begin{array}{l}\text { NHANES 2001-2002 } \\
(n \text { 620) }\end{array}$} & \multirow[b]{2}{*}{$P$ value* } & \multirow{2}{*}{$\begin{array}{l}\text { Percentage } \\
\text { difference† }\end{array}$} \\
\hline & & Mean & SE & Mean & SE & & \\
\hline Total HEI-2005 score & $0-100$ & $61 \cdot 9$ & $0 \cdot 75$ & $57 \cdot 4$ & 0.55 & $<0.01$ & $7 \cdot 3$ \\
\hline 1. Total fruit (includes $100 \%$ juice) & $0-5$ & $3 \cdot 27$ & 0.09 & $3 \cdot 18$ & 0.08 & 0.78 & $2 \cdot 8$ \\
\hline 2. Whole fruit (not juice) & $0-5$ & 3.53 & $0 \cdot 10$ & $3 \cdot 17$ & 0.09 & 0.03 & $10 \cdot 2$ \\
\hline 3. Total vegetables & $0-5$ & $3 \cdot 75$ & 0.07 & $3 \cdot 40$ & 0.07 & $<0.01$ & $9 \cdot 3$ \\
\hline $\begin{array}{l}\text { 4. Dark green and orange vegetables } \\
\text { and legumes }\end{array}$ & $0-5$ & $2 \cdot 04$ & $0 \cdot 11$ & $1 \cdot 39$ & 0.07 & $<0.01$ & $31 \cdot 9$ \\
\hline 5. Total grains & $0-5$ & $4 \cdot 68$ & 0.04 & $4 \cdot 44$ & 0.04 & $<0.01$ & $5 \cdot 1$ \\
\hline 6. Whole grains & $0-5$ & $3 \cdot 22$ & $0 \cdot 11$ & 1.65 & 0.07 & $<0.01$ & $48 \cdot 8$ \\
\hline 7. Milk & $0-10$ & $3 \cdot 76$ & $0 \cdot 11$ & $5 \cdot 42$ & $0 \cdot 14$ & $<0.01$ & $-44 \cdot 1$ \\
\hline 8. Meat and beans & $0-10$ & $9 \cdot 15$ & 0.09 & $7 \cdot 90$ & $0 \cdot 11$ & $<0.01$ & $13 \cdot 7$ \\
\hline 9. Oil & $0-10$ & $6 \cdot 12$ & $0 \cdot 18$ & $5 \cdot 70$ & $0 \cdot 14$ & 0.01 & $6 \cdot 9$ \\
\hline 10. Saturated fat & $0-10$ & $5 \cdot 86$ & $0 \cdot 18$ & $6 \cdot 38$ & $0 \cdot 14$ & 0.03 & -8.9 \\
\hline 11. Sodium & $0-10$ & 3.55 & $0 \cdot 16$ & 3.55 & $0 \cdot 12$ & 0.44 & 0.0 \\
\hline $\begin{array}{l}\text { 12. Energy from solid fat, alcoholic } \\
\text { beverages and added sugar }\end{array}$ & $0-20$ & $12 \cdot 98$ & 0.34 & $11 \cdot 21$ & 0.26 & $<0.01$ & $13 \cdot 6$ \\
\hline
\end{tabular}

HEI-2005, Healthy Eating Index-2005; GRAS, Geisinger Rural Aging Study; NHANES, National Health and Nutrition Examination Study.

${ }^{*} P$ values obtained from Student's $t$ tests.

tThe percentage difference was determined by the following calculation for the summary score and for each component score: ([GRAS mean score-NHANES mean score]/GRAS mean score) $\times 100$.

the percentage of total energy from fat were significantly greater in NHANES compared with GRAS. The percentage of total energy from protein and dietary fibre intake per $4 \cdot 2 \mathrm{~kJ}$ was significantly greater in GRAS (all $P$ values $<0 \cdot 05)$. Energy-adjusted dietary intakes of calcium, vitamin $\mathrm{C}$ and folate did not differ significantly between samples.

Table 3 presents results from the comparisons of HEI-2005 total and component scores between GRAS and NHANES. The total fruit and sodium component scores did not differ significantly between samples, whereas scores on the remaining ten components, as well as the total score, differed significantly at $P<0 \cdot 05$. Percentage differences between samples show the degree to which scores differed. Of the twelve component scores, seven, as well as the summary score, differed by $<10 \%$. Sodium component scores were identical in GRAS and NHANES. The largest percentage difference between samples was for whole grains $(48 \cdot 8 \%)$.

Cronbach's coefficient $\alpha$ values of 0.52 and 0.43 were calculated for the HEI-2005 scale in GRAS and NHANES, respectively. The individual component scores most strongly correlated with the total score - less the specified component in the correlation test - in GRAS were the SoFAAS $(0 \cdot 60)$, saturated fat $(0 \cdot 53)$, whole fruit $(0 \cdot 43)$, total vegetables $(0 \cdot 43)$ and total fruit $(0 \cdot 40)$ components (all $P<0 \cdot 001)$. In the NHANES data, HEI-2005 was most 
strongly correlated with the SoFAAS $(0.55)$, total fruit $(0 \cdot 39)$, saturated fat $(0 \cdot 33)$ and whole fruit $(0 \cdot 31)$ components (all $P<0 \cdot 001$; data not shown).

\section{Discussion}

Findings from the present study indicate that the specific and detailed guidelines established by the CNPP to calculate HEI-2005 ${ }^{(43)}$ can be applied to other dietary data analysis systems such as NDSR. Generating component scores in NDSR for total fruit, whole fruit, total vegetables, dark green and orange vegetables and legumes, total grains, milk, meat and beans, saturated fat and sodium corresponds closely to the method described in the CNPP technical report. There is a key distinction between FNDDS and NDSR, which explains the need for additional steps to calculate the whole grain, oil and SoFAAS components with NDSR. NDSR does not separate most packaged and store-bought whole food items (e.g. packaged snack items, ready-to-eat cereal and pre-made soup) into individual ingredients, although it does separate home-made recipes and formulas into individual ingredients. On the other hand, MPED separates all food mixtures into single ingredients. For this reason, the food group serving files rather than the food ingredient files were used to calculate the whole grain component, which offers a potential explanation for the greater whole grain component score in GRAS $(3 \cdot 22)$ compared with NHANES (1.65). The food group serving files in GRAS divide whole grains into three categories ('whole', 'some' and 'refined'), and since the 'some' whole grain food items were considered to be one-half whole grain and one-half refined, whole grain intake may have been overestimated in GRAS. The availability of whole grain products and the composition of grain products in the US food supply between the NHANES data collection period (2001-2002) and the GRAS data collection period (2004-2005) have increased ${ }^{(45)}$, which may partially explain the estimated difference in the whole grain component scores between study populations. Although minor adjustments to the CNPP method for calculating oil and SOFAAS scores were required, the small percentage differences in component scores between GRAS and NHANES suggest that these modifications may not substantially alter the estimation of scores.

Differences in HEI-2005 total and component scores between samples may be partially explained by additional differences beyond those related to the dietary data analysis systems. Despite the selection of an age- and race-matched subset of the NHANES sample, the two study populations differed with regard to several demographic characteristics and dietary intake factors. GRAS is a nutritional-risk screening study of older adults residing in rural Pennsylvania, whereas NHANES is a study designed to provide nationally representative estimates for the health and nutritional status of the civilian, noninstitutionalized US population; dietary intake patterns and overall diet quality may vary significantly by geographic region ${ }^{(24,46)}$. GRAS participants completed four $24 \mathrm{~h}$ dietary recalls in 2004-2005, whereas NHANES participants completed one $24 \mathrm{~h}$ dietary recall in 2001-2002. The different time frames of dietary data collection may have influenced the observed differences in HEI-2005 scores, although the extent of this influence is most likely small since dietary intake habits and patterns, particularly among older adults, have been shown to be relatively stable over a 3-5-year period ${ }^{(47,48)}$. A greater percentage of GRAS participants compared with NHANES participants completed high school, and higher levels of educational attainment have been associated with increased measures of overall diet quality ${ }^{(49)}$. The lower mean SoFAAS score, which reflects higher intakes of saturated fat, trans fat, alcoholic beverages and/or added sugar, in NHANES was most likely related to the greater percentage of total energy from fat. It may also be related to the higher scores observed in the milk component, which reflects greater intakes of both high-fat dairy products and lower-fat varieties. The modestly higher energy-adjusted intakes of dietary fibre, vitamin $\mathrm{C}$ and folate in GRAS are reflected in the higher scores in the four fruit and vegetable components as well as the whole grain component; the higher proportion of energy from protein in GRAS is reflected in the higher meat and beans score.

The internal consistency of the HEI-2005 as measured by Cronbach's coefficient $\alpha$ is low in both GRAS $(0.52)$ and NHANES $(0 \cdot 43)^{(50)}$. Since diet quality is a complex, multi-dimensional construct ${ }^{(51,52)}$, it is expected that most individuals would not consistently achieve high or low scores on all twelve individual components. Very high and very low summary scores most likely would reflect similar underlying dietary patterns. Mid-range scores, however, would not necessarily reflect similar dietary patterns because such scores could be achieved with midrange scores on all of the individual components that comprise the index, or with various combinations of minimum, mid-range and maximum scores on the individual components ${ }^{(29,52)}$. Results from evaluating internal consistency in GRAS suggest that HEI-2005 scores generated using NDSR do not significantly alter the implication and interpretation of scores.

The HEI-2005 has a number of applications, including evaluations of community-based lifestyle interventions, population-level surveillance of overall diet quality, evaluations of educational initiatives and epidemiological investigations of diet-disease associations. By exploring the individual HEI-2005 components in a population, key areas of concern could be identified, which could provide guidance for the development of public policies and prevention efforts to improve public health ${ }^{(53)}$. It is important to develop and evaluate methods for generating scores with commonly used data analysis software 
applications and food composition databases such as NDSR and its accompanying food and nutrient databases $^{(30,31)}$. Our findings show that HEI-2005 scores can be generated with NDSR using the method described in the present study and the USDA CNPP's detailed report ${ }^{(6)}$ as guidance.

\section{Acknowledgements}

The present research was supported by funding from the US Department of Agriculture (Grant no. 58-1950-6019). There are no conflicts of interest. P.E.M. performed the literature review, contributed to the study design and method development, planned and conducted the statistical analyses, and wrote the manuscript. D.C.M. contributed to the study design and method development, contributed to interpretation of the findings and reviewed drafts of the manuscript. P.L.H. and J.M.P. contributed to content analysis and reviewed drafts of the manuscript. T.J.H. helped conceptualize ideas, contributed to the study design and statistical analysis of the data and reviewed drafts of the manuscript. All authors have read and approved the final paper.

\section{References}

1. Kant AK (2004) Dietary patterns and health outcomes. J Am Diet Assoc 104, 615-635.

2. Nkondjock A \& Ghadirian P (2007) Diet quality and BRCAassociated breast cancer risk. Breast Cancer Res Treat 103, 361-369.

3. Patterson RE, Haines PS \& Popkin BM (1994) Diet quality index: capturing a multidimensional behavior. $J$ Am Diet Assoc 94, 57-64.

4. Kant AK, Schatzkin A, Graubard BI et al. (2000) A prospective study of diet quality and mortality in women. JAMA 283, 2109-2115.

5. Reedy J, Mitrou PN, Krebs-Smith SM et al. (2008) Indexbased dietary patterns and risk of colorectal cancer: the NIH-AARP Diet and Health Study. Am J Epidemiol 168, 38-48.

6. Guenther PM, Reedy J \& Krebs-Smith SM (2008) Development of the Healthy Eating Index-2005. J Am Diet Assoc 108, 1896-1901.

7. McCullough ML, Feskanich D, Stampfer MJ et al. (2002) Diet quality and major chronic disease risk in men and women: moving toward improved dietary guidance. Am J Clin Nutr 76, 1261-1271.

8. Trichopoulou A, Costacou T, Bamia C et al. (2003) Adherence to a Mediterranean diet and survival in a Greek population. N Engl J Med 348, 2599-2608.

9. Kennedy ET, Ohls J, Carlson S et al. (1995) The Healthy Eating Index: design and applications. J Am Diet Assoc 95 , 1103-1108.

10. Kim S, Haines PS, Siega-Riz AM et al. (2003) The Diet Quality Index-International (DQI-I) provides an effective tool for cross-national comparison of diet quality as illustrated by China and the United States. J Nutr 133, 3476-3484.

11. Clutter Snyder D, Sloane R, Haines PS et al. (2007) The Diet Quality Index revised: a tool to promote and evaluate dietary change among older cancer survivors enrolled in a home-based intervention trial. J Am Diet Assoc 107, 1519-1529.

12. Dwyer J, Cosentino C, Li D et al. (2002) Evaluating schoolbased interventions using the Healthy Eating Index. $J \mathrm{Am}$ Diet Assoc 102, 257-259.

13. Morey M, Snyder DC, Sloane R et al. (2009) RENEW: a randomized clinical trial to improve function among older long-term survivors of breast, prostate and colorectal cancer. JAMA 301, 1883-1891.

14. Couch SC, Saelens BE, Levin L et al. (2008) The efficacy of a clinic-based behavioral nutrition intervention emphasizing a DASH-type diet for adolescents with elevated blood pressure. J Pediatr 152, 494-501.

15. Sarrafzadegan N, Azadbakht L, Mohammadifard $\mathrm{N}$ et al. (2009) Do lifestyle interventions affect dietary diversity score in the general population? Public Health Nutr 12, 1-7.

16. Kennedy ET, Bowman SA, Spence JT et al. (2001) Popular diets: correlation to health, nutrition, and obesity. J Am Diet Assoc 101, 411-420.

17. Haines PS, Siega-Riz AM \& Popkin BM (1999) The Diet Quality Index revised: a measurement instrument for populations. J Am Diet Assoc 99, 697-704.

18. Tur JA, Romaguera D \& Pons A (2005) The Diet Quality Index-International (DQI-I): is it a useful tool to evaluate the quality of the Mediterranean diet? Br J Nutr 93, 369-376.

19. Neuhouser ML, Patterson RE, King IB et al. (2003) Selected nutritional biomarkers predict diet quality. Public Health Nutr 6, 703-709.

20. Fung TT, Hu FB, McCullough ML et al. (2006) Diet quality is associated with the risk of estrogen receptor-negative breast cancer in postmenopausal women. J Nutr 136, 466-472.

21. Gao SK, Beresford SA, Frank LL et al. (2008) Modifications to the Healthy Eating Index and its ability to predict obesity: the Multi-Ethnic Study of Atherosclerosis. Am J Clin Nutr 88, 64-69.

22. Guo X, Warden BA, Paeratakul S et al. (2004) Healthy Eating Index and obesity. Eur J Clin Nutr 58, 1580-1586.

23. Fung TT, McCullough ML, Newby PK et al. (2005) Dietquality scores and plasma concentrations of markers of inflammation and endothelial dysfunction. Am J Clin Nutr 82, 163-173.

24. Shannon J, Shikany JM, Barrett-Connor E et al. (2007) Demographic factors associated with the diet quality of older US men: baseline data from the Osteoporotic Fractures in Men (MrOS) Study. Public Health Nutr 10, $810-818$.

25. Levitan EB, Wolk A \& Mittleman MA (2009) Consistency with the DASH diet and incidence of heart failure. Arch Intern Med 169, 851-857.

26. US Department of Health and Human Services \& US Department of Agriculture (2005) Dietary Guidelines for Americans, 2005, 6th ed. Washington, DC: Government Printing Office.

27. Britten P, Marcoe K, Yamini S et al. (2006) Development of food intake patterns for the MyPyramid food guidance system. J Nutr Educ Behav 38, S78-S92.

28. Friday JE \& Bowman SA (2006) MyPyramid Equivalents Database for USDA Survey Food Codes, 1994-2002, Version 1.0. http://www.ars.usda.gov/Services/docs. htm?docid $=8498$ (accessed October 2008).

29. Guenther PM, Reedy J, Krebs-Smith SM et al. (2008) Evaluation of the Healthy Eating Index-2005. J Am Diet Assoc 108, 1854-1864.

30. Zimmerman TP, Stumbo P, Chenard C et al. (2008) Databank Directory Committee of the National Nutrient Databank Conference. 2008 International Nutrient Databank Directory. http://www.healthcare.uiowa.edu/gcrc/ nndc/survey.html 
31. Probst YC \& Tapsell LC (2005) Overview of computerized dietary assessment programs for research and practice in nutrition education. I Nutr Educ Behav 37, 20-26.

32. Harrington KF, Kohler CL, McClure LA et al. (2009) Fourth graders' reports of fruit and vegetable intake at school lunch: does treatment assignment affect accuracy? $J \mathrm{Am}$ Diet Assoc 109, 36-44.

33. Ledikwe JH, Smiciklas-Wright H, Mitchell DC et al. (2004) Dietary patterns of rural older adults are associated with weight and nutritional status. J Am Geriatr Soc 52, 589-595.

34. Miller P, Demark-Wahnefried W, Snyder DC et al. (2008) Dietary supplement use among elderly, long-term cancer survivors. J Cancer Surviv 2, 138-148.

35. Quatromoni PA, Pencina M, Cobain MR et al. (2006) Dietary quality predicts adult weight gain: findings from the Framingham Offspring Study. Obesity (Silver Spring) 14, 1383-1391.

36. Yesavage JA, Brink TL, Rose TL et al. (1982) Development and validation of a geriatric depression screening scale: a preliminary report. J Psychiatr Res 17, 37-49.

37. Folstein MF, Folstein SE \& McHugh PR (1975) 'Mini-mental state'. A practical method for grading the cognitive state of patients for the clinician. J Psychiatr Res 12, 189-198.

38. Bailey RL, Mitchell DC, Miller CK et al. (2007) A dietary screening questionnaire identifies dietary patterns in older adults. J Nutr 137, 421-426.

39. National Center for Health Statistics, Center for Disease Control and Prevention (2004) NHANES 2001-2002 Public Data General Release File Documentation. Atlanta, GA: National Center for Health Statistics; available at http:// www.cdc.gov/nchs/data/nhanes/nhanes_01_02/general_ data_release.doc.pdf

40. National Center for Health Statistics, Center for Disease Control and Prevention (1996) NHANES III Anthropometric Procedures (video). Stock number 017-022-01335-5. Washington, DC: Government Printing Office.

41. Jonnalagadda SS, Mitchell DC, Smiciklas-Wright $\mathrm{H}$ et al. (2000) Accuracy of energy intake data estimated by a multiple-pass, 24-hour dietary recall technique. J Am Diet Assoc 100, 303-308; quiz 309-311.

42. Tran KM, Johnson RK, Soultanakis RP et al. (2000) Inperson vs telephone-administered multiple-pass 24-hour recalls in women: validation with doubly labeled water. J Am Diet Assoc 100, 777-783.
43. Guenther PM, Reedy J, Krebs-Smith SM, et al. (2007) Development and Evaluation of the Healthy Eating Index-2005: Technical Report. Alexandria, VA: Center for Nutrition Policy and Promotion, US Department of Agriculture; available at http://www.cnpp.usda.gov/ HealthyEatingIndex.htm

44. Willett WC, Howe GR \& Kushi LH (1997) Adjustment for total energy intake in epidemiologic studies. Am J Clin Nutr 65, 1220S-1228S; discussion 1229S-1231S.

45. Hiza H, Fungwe T, Bente L (2007) Trends in Dietary Fiber in the US Food Supply; Sales of Grain Products. Alexandria, VA: Center for Nutrition Policy and Promotion, US Department of Agriculture; available at http://www.cnpp.usda.gov/ Publications/FoodSupply/FiberFactSheet.pdf

46. Moore LV, Diez Roux AV, Nettleton JA et al. (2008) Associations of the local food environment with diet quality - a comparison of assessments based on surveys and geographic information systems: the MultiEthnic Study of Atherosclerosis. Am J Epidemiol 167, 917-924.

47. Willett WC, Sampson L, Browne ML et al. (1988) The use of a self-administered questionnaire to assess diet four years in the past. Am J Epidemiol 127, 188-199.

48. Goldbohm RA, van 't Veer P, van den Brandt PA et al. (1995) Reproducibility of a food frequency questionnaire and stability of dietary habits determined from five annually repeated measurements. Eur J Clin Nutr 49, 420-429.

49. Popkin BM, Zizza C \& Siega-Riz AM (2003) Who is leading the change? US dietary quality comparison between 1965 and 1996. Am J Prev Med 25, 1-8.

50. Bland JM \& Altman DG (1997) Statistics notes: Cronbach's alpha. BMJ 314, 572.

51. Popkin BM, Haines PS \& Siega-riz AM (1999) Dietary patterns and trends in the United States: the UNC-CH approach. Appetite 32, 8-14.

52. Moeller SM, Reedy J, Millen AE et al. (2007) Dietary patterns: challenges and opportunities in dietary patterns research an experimental biology workshop, 1 April 2006. J Am Diet Assoc 107, 1233-1239.

53. Huot I, Paradis G, Receveur O et al. (2004) Correlates of diet quality in the Quebec population. Public Health Nutr 7, 1009-1016. 